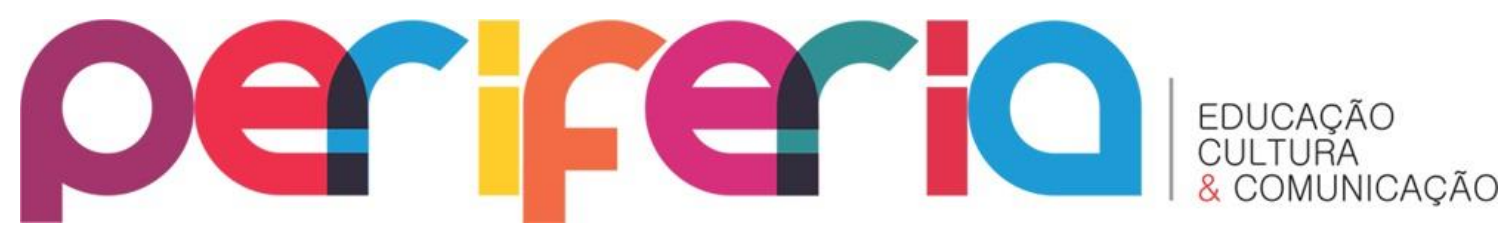

\title{
ESTÁGIO EM AMBIENTES NÃO ESCOLARES: a pesquisa formando o educador do campo para transformação social
}

\author{
Kleber Peixoto de Souza ${ }^{1}$ \\ Leila Damiana Almeida dos Santos Souza²
}

\section{Resumo}

O artigo apresenta a análise do Estágio Curricular em Ambientes Não Escolares ao longo da trajetória político-educativa do curso de Licenciatura em Educação do Campo (LEdoC), do Centro de Ciência e Tecnologia em Energia e Sustentabilidade da UFRB. O curso se estrutura a partir dos princípios da Pedagogia da Alternância que, por sua vez, organiza-se em dois tempos formativos: o Tempo-Universidade (TU) e o Tempo-Comunidade (TC). Ao longo dos sete anos (2013-2020) de existência do curso acumulamos experiências que nos permitem acreditar que o êxito na formação dos (as) discentes requer a integração de métodos e instrumentos específicos que garantam a unicidade dos conhecimentos produzidos no TU e sua aplicação no TC. Assim, objetivamos analisar o alcance da organização do Estágio Curricular, por meio da pesquisa participante, na formação do (a) educador (a) do campo. As análises qualitativas das representações dos (as) discentes sobre este Estágio, bem como a análise de relatórios produzidos pelos mesmos, são os condutores da metodologia empregada. Ressaltamos então que, com a pesquisa participante os discentes estabelecem contato direto com a realidade, possibilitando uma interação que permite construir coletivamente soluções que promovam a transformação social. Como resultado, foi possível constatar que, em se tratando do Estágio em Ambientes Não Escolares da LEdoC, reduzi-lo apenas a uma etapa do aprendizado profissional acabaria por limitar as potencialidades do mesmo, portanto, estruturar o Estágio como uma pesquisa participante contribuiu para superação da dicotomia entre a teoria e prática que, geralmente, permeia esse componente curricular.

Palavras-chave: Ambientes Não Escolares; Estágio; Pesquisa Participante; Transformação Social.

\footnotetext{
${ }_{1}^{1}$ Mestrado em Educação na Faculdade de Educação da Universidade de Brasília (FE/UnB) (2006). É doutorando em Ciências da Educação pela Universidade do Minho - Portugal, em parceria com a Universidade Federal do Recôncavo da Bahia (UFRB). Instituição: Universidade Federal do Recôncavo da Bahia (UFRB). ORCID iD: https://orcid.org/0000-0003-4940-1465. E-mail: kleber.peixoto@ufrb.edu.br.

2 Pedagoga, com Doutorado e Mestrado no Programa Multidisciplinar de Pós-Graduação em Cultura e Sociedade, da Universidade Federal da Bahia (UFBA). Instituição: Universidade Federal do Recôncavo da Bahia (UFRB). ORCID iD: https://orcid.org/0000-0001-8491-2194. Email: leila.damiana@ufrb.edu.br.
} 


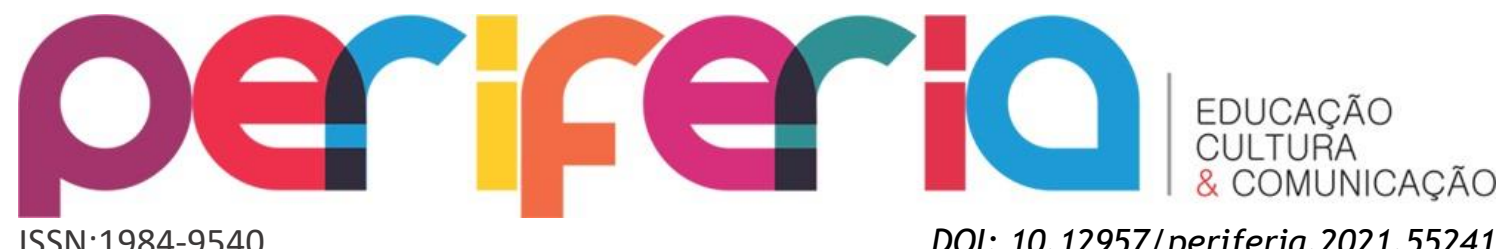

INTERNSHIP IN NON-SCHOOL ENVIRONMENTS: research training rural educators for social transformation

\section{Abstract}

The article presents analyzes of the Curricular Internship in Non-School Environments along the political-educational trajectory of the Degree Course in Rural Education (LEdoC), at the Center for Science and Technology in Energy and Sustainability at UFRB. The course is structured around the principles of Pedagogy of Alternation, which, in turn, is organized into two formative periods: Time-University (TU) and Time-Community (TC). Over the seven years (2013-2020) of the course's existence, we have accumulated experiences that allow us to believe that success in the training of students requires the integration of specific methods and instruments that guarantee the uniqueness of the knowledge produced in the TU and its application on the TC. Thus, we aim to analyze the scope of the organization of the Curricular Internship, through participatory research, in the education of the field educator. The qualitative analyzes of the students' representations about this Internship, as well as the analysis of reports produced by them, are the drivers of the methodology used. We emphasize that, with the participant research, the students establish direct contact with reality, allowing an interaction that allows to collectively build solutions that promote social transformation. As a result, it was possible to verify that, in the case of LEdoC's Internship in NonSchool Environments, reducing it to just one stage of professional learning would limit its potential, therefore, structuring the Internship as a participant research contributed to overcoming the dichotomy between theory and practice that usually permeates this curricular component.

Keywords: Non-School Environments; Internship; Participating Research; Social Transformation.

\section{PRÁCTICAS EN ENTORNOS NO ESCOLARES: investigación y formación de educadores rurales para la transformación social}

\section{Resumen}

El artículo presenta análisis del Pasantía Curricular en Ambientes No Escolares a lo largo de la trayectoria político-educativa de la Licenciatura en Educación Rural (LEdoC), en el Centro de Ciencia y Tecnología en Energía y Sustentabilidad de la UFRB. El curso se estructura en base a los principios de la Pedagogía de la Alternancia, que a su vez se organiza en dos periodos formativos: Tiempo- 


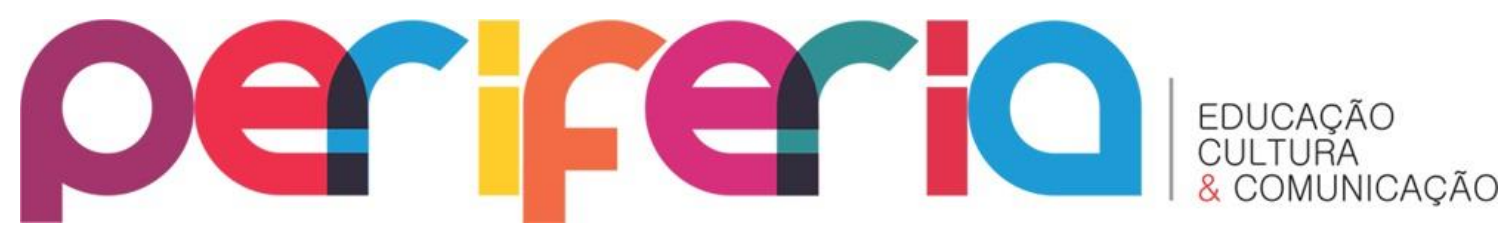

ISSN:1984-9540

DOI: $10.12957 /$ periferia.2021.55241

Universidad (TU) y Tiempo-Comunidad (TC). A lo largo de los siete años (20132020) de existencia del curso, hemos acumulado experiencias que nos permiten creer que el éxito en la formación de los estudiantes requiere la integración de métodos e instrumentos específicos que garanticen la singularidad de los conocimientos producidos en la TU y su aplicación. en el TC. Así, nos proponemos analizar el alcance de la organización de la Práctica Curricular, a través de la investigación participativa, en la formación del educador de campo. Los análisis cualitativos de las representaciones de los estudiantes sobre esta pasantía, así como el análisis de los informes elaborados por ellos, son los motores de la metodología utilizada. Destacamos que, con la investigación participante, los estudiantes establecen un contacto directo con la realidad, permitiendo una interacción que permite construir colectivamente soluciones que promuevan la transformación social. Como resultado, se pudo constatar que, en el caso de la Práctica en Entornos No Escolares de LEdoC, reducirla a una sola etapa de aprendizaje profesional limitaría su potencial, por lo tanto, estructurar la Práctica como una investigación participante contribuyó a superar la dicotomía entre teoría y práctica que habitualmente impregna este componente curricular.

Palabras clave: Ambientes no escolares; Prácticas; Investigación participante; Transformación social.

\section{INTRODUÇÃO}

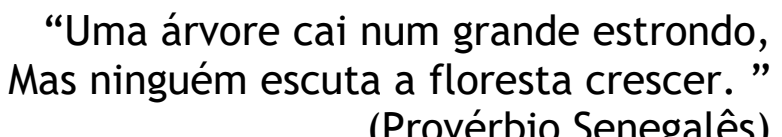

(Provérbio Senegalês)

A necessidade de um olhar para além das coisas aparentes conduziram nossos objetivos e análises acerca do Estágio Curricular em Ambientes Não Escolares, tendo como foco de análise a metodologia da Pesquisa Participante. Ao adentrarmos na essência e nas possibilidades desse Estágio, necessariamente partimos de uma breve caracterização do Curso de Licenciatura em Educação do Campo do Centro de Ciência e Tecnologia em Energia e Sustentabilidade, da Universidade Federal do Recôncavo da Bahia.

Apresentamos neste artigo uma perspectiva de Estágio Curricular orientada pelos pressupostos da Pesquisa Participante. Trata-se de vivências acumuladas na Educação do Campo que nos permitem romper com organização tradicional dos Estágios. Sabendo que, em muitos cursos de formação de 


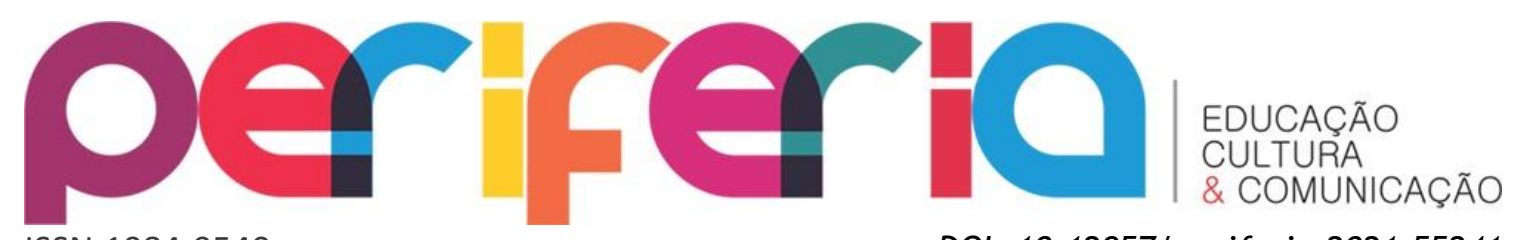

ISSN:1984-9540

DOI: $10.12957 /$ periferia.2021.55241

professores, os Estágios são orientados por atividades que primam pelo pacto do silêncio e por ações reprodutivas, oferecemos um contraponto. Ou seja, apresentamos um Estágio em Ambientes Não Escolares que se operacionaliza na relação dialógica entre as aprendizagens teórico-práticas do TempoUniversidade e as atividades teórico-práticas do Tempo-Comunidade.

Para compreender a forma com que se estrutura esse Estágio, faz-se necessário uma contextualização da organização curricular da Licenciatura em Educação do Campo. Desta forma, apresentamos alguns princípios e fundamentos basilares do curso desenvolvido no Centro de Ciência e Tecnologia em Energia e Sustentabilidade.

Apresentamos ainda os fundamentos epistemológicos que permitem organizar os Estágios em Ambientes Não Escolares permeado pela pesquisa participante. Assim, enfatizamos as linhas metodológicas que vêm possibilitando experiências exitosas com estes Estágios.

\section{O ESTÁGIO EM AMBIENTES NÃO ESCOLARES NA ORGANIZAÇÃO CURRICULAR DA LICENCIATURA EM EDUCAÇÃO DO CAMPO}

Os Estágios Curriculares em cursos de formação de professores, em muitos casos, encontram-se envoltos por uma "lógica muda e míope, em que os componentes se aglomeram de forma isolada e sem nexos umas com as outras, constituindo-se assim, em aglomerados de saberes disciplinares, extremamente distantes da realidade cotidiana e do campo de trabalho dos futuros profissionais da educação" (SOUZA, 2012, p. 190).

Já na elaboração da Proposta Pedagógica do Curso nos preocupamos na busca de alternativas para romper com a dicotomia teoria-prática. Nos balizamos pelos princípios políticos-epistemológicos da Educação do Campo, bem como nos aspectos estruturantes da Pedagogia da Alternância.

Amparados por esses princípios e fundamentos estão os Estágios Curriculares. Na busca para gestar uma organização curricular onde a dicotomização entre as dimensões teoria e prática não tornasse os Estágios o "salvador da prática", o curso de Licenciatura em Educação do Campo se 


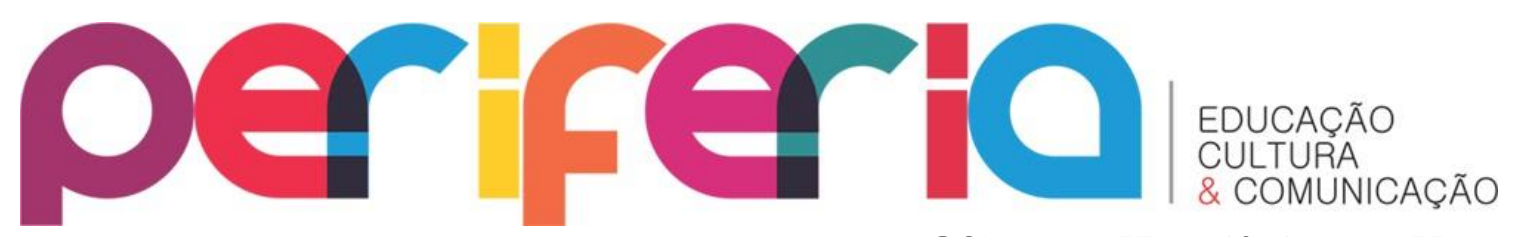

ISSN:1984-9540

DOI: $10.12957 /$ periferia.2021.55241

estruturou em dois tempos formativos intercomunicantes (Tempo-Universidade

e Tempo-Comunidade). Os cursos, com habilitações em Ciências da Natureza e Matemática, nascem com o compromisso de pensar o desenvolvimento do campo com os campesinos, e não apenas pensar para eles.

A Pedagogia da Alternância nos aponta caminhos para integrarmos as atividades do Tempo-Universidade (TU) e do Tempo-Comunidade (TC). 0 chamado T.U. estrutura-se de modo a possibilitar uma organização do tempo pessoal e o tempo coletivo dos discentes e docentes em relação aos objetivos do processo formativo pretendido, tanto na dimensão acadêmica, quanto na auto-organização. Já o TC, compreende o exercício da prática pedagógica e será desenvolvido nos locais de moradia/trabalho dos estudantes. De acordo com o Projeto Pedagógico do Curso, "o olhar diferenciado para estes espaços é mediatizado por estudos dirigidos, práticas docentes, oficinas, pesquisas, estágios curriculares e intervenções devidamente acompanhados por professores orientadores das diferentes áreas do conhecimento" (PPC, 2013, p. 69).

Não se pode perder de vista outro importante tempo formativo, o Tempo Organicidade. Ressaltamos que a organicidade necessária para configuração de um coletivo deve ser concebida como "a capacidade que um Movimento tem de fazer com que as ideias, discussões e orientações comuns percorram e se articulem, em todo o corpo da organização, de forma permanente" (PELOSO, 2012, p. 54). Ainda segundo o autor, o fluxo constante da organicidade "garante a unidade de pensamento e de ação, com autonomia relativa das partes, para aplicar, de maneira criativa, suas decisões gerais, além de cuidar da sua auto reprodução". (PELOSO, 2012, p. 54). Diante desta compreensão, torna-se necessário demarcar que no Projeto Pedagógico do Curso são apresentadas quatro instâncias do Tempo Organicidade:

O Tempo Organicidade exerce, dentro do currículo do curso, uma função extremamente importante, necessária e coerente com a proposta pedagógica e com a metodologia adotada pelo mesmo. O tempo organicidade na LEDOC é estruturado em quatro instâncias distintas e interligadas, a saber: 0 Grupo de Organicidade (GO) tem a função de refletir e fazer uma análise crítica sobre as atividades referentes ao processo organizativo. As atividades relativas ao Setor de trabalho (ST) pressupõem que 


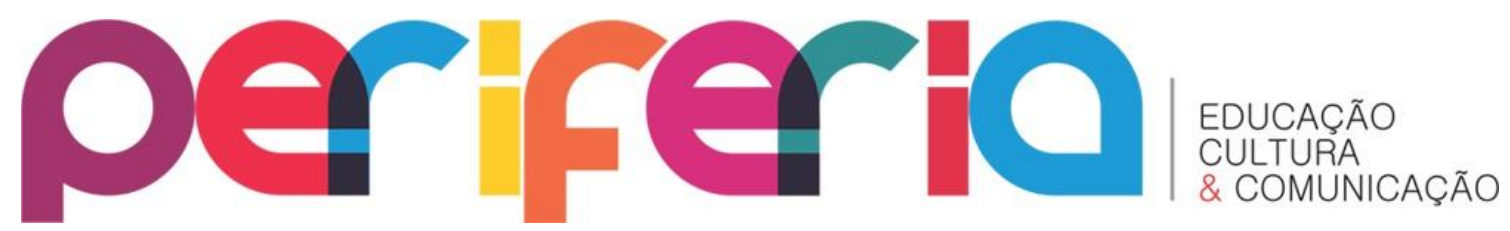

DOI: $10.12957 /$ periferia.2021.55241

a vida em grupo requer a participação de todos na organização geral do espaço. A Coordenação Político Pedagógica (CPP) é constituída por alunos representantes de turmas, docentes da licenciatura, coordenadores dos grupos de organicidades e dos grupos dos setores de trabalho. O CPP objetiva fazer 0 planejamento pedagógico da etapa. Por fim, a Plenária discente (PD). (PPC, 2018, p. 78)

Os métodos e instrumentos da Pedagogia da Alternância nos permite acompanhar o Tempo-Comunidade ao passo que integramos as atividades a serem desenvolvidas com as aprendizagens construídas no Tempo-Universidade. Assim, à luz do regime de alternância, nos valemos para orientar, acompanhar e avaliar o Tempo-Comunidade de instrumentos como: o Plano de Estudos e o Caderno da Realidade.

O Plano de Estudo consiste numa orientação voltada para organização das atividades didático-metodológicas a serem realizadas no meio sócio profissional, ou seja, nas comunidades dos discentes. Trata-se de uma ação participativa guiada por uma sistematização que, por sua vez, é ampliada no TU através de diferentes atividades de formação. Nos planos serão solicitadas atividades de pesquisa, estudos dirigidos e leituras de textos, encaminhamentos das ações interdisciplinares do Seminário Integrador, atividades dos diversos componentes curriculares. Integram também os Planos, as Visitas de Estudos, estas realizadas em escolas do campo ou em espaços não escolares, tendo como objetivo perceber os desafios e as contradições das mesmas, e também desenvolver atividades pedagógicas nestes espaços, subsidiadas nos temas estudados nos diversos componentes curriculares (PPC, 2013, p. 62).

O outro instrumento denominado Caderno da Realidade é um procedimento didático e avaliativo estritamente integrado ao Plano de Estudo. As produções escritas e registradas do Caderno possibilitam análises a partir das observações e intervenções desenvolvidas nas comunidades. De acordo com o PPC do Curso (2013, p. 62), “o Caderno da Realidade é um instrumento básico para o trabalho interdisciplinar, nele registra-se as constatações e as reflexões sobre a realidade educacional do campo, familiar e sócio profissional”.

Para promover a integração das atividades dos dois tempos formativos a perspectiva interdisciplinar precisa ir além de um simples adorno curricular. Ou 


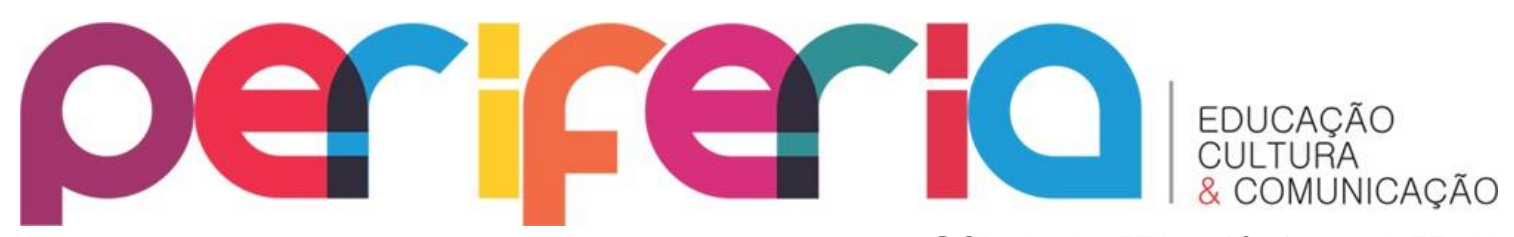

ISSN:1984-9540

DOI: 10.12957/periferia.2021.55241

seja, pensamos que ao garantirmos na organização curricular um momento presencial e coletivo para planejar, avaliar e socializar as construções daríamos um importante passo para termos um currículo em movimento. Esse momento foi operacionalizado como componente curricular, denominado Seminário Integrador. Estão presentes em todos os semestres do curso e tem como objetivo "promover a articulação das diferentes áreas de conhecimento, enriquecendo a construção das pesquisas e práticas pedagógicas a serem desenvolvidas no tempo-comunidade" (PPC, 2013, p. 62).

Essa organização curricular diferenciada se deve ao fato de que existe uma "diversidade dos modos de produção de vida dos sujeitos do campo, e esta indica forte descompasso entre a lógica generalista do sistema educacional e as especificidades do território rural" (MOLINA, MONTENEGRO, OLIVEIRA, 2009. p. 174). Entendendo que as especificidades da Educação do Campo precisam ser pautadas na construção de propostas pedagógicas para os campesinos, defendemos que uma perspectiva curricular inovadora necessariamente precisa contribuir para o "enfrentamento destas iniquidades, em função das variadas consequências que geram ao negar o desenvolvimento amplo e integral não só destes indivíduos, mas também das comunidades rurais as quais pertencem". (MOLINA, MONTENEGRO, OLIVEIRA, 2009, p. 175).

Desse modo, pensar a estrutura de um curso mirando um processo formativo de totalidade, conforme defende Gaudêncio Frigotto (1996), nos levou a um processo de elaboração numa perspectiva omnilateral. Perspectiva essa em que as pessoas vêm em primeiro lugar, e devem ter minimamente garantido um conjunto de direitos fundamentais, a começar pelo direito à vida digna, à saúde, à educação, habitação e emprego, dentre outros. (FRIGOTTO, 1996, p. 157). Ainda sobre a perspectiva omnilateral é possível afirmar que:

Idealizamos então um processo formativo que estivesse preocupado com uma perspectiva científico-crítica, em que o desenvolvimento integral do homem, numa perspectiva ominilateral estivesse posta. Contribuímos na formulação de uma proposta que buscou romper com as dualidades teoria e prática; pensamento e ação; homem e sociedade; pedagógico, o político e o social, dentre outras. Uma formação do homem 


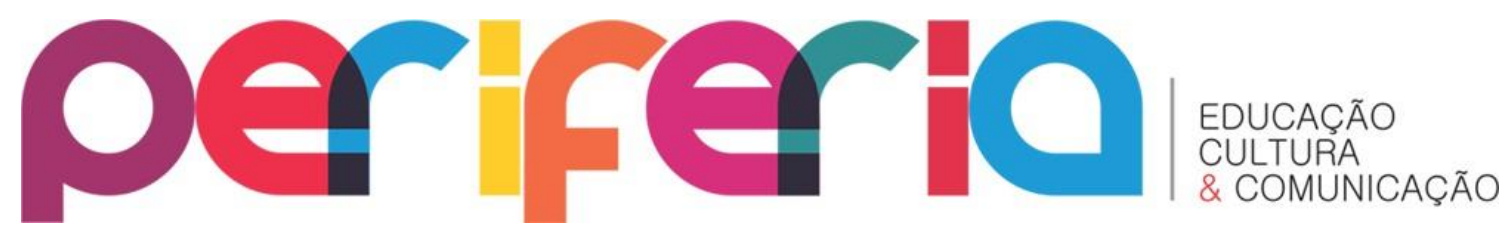

completo que se perceba como parte do mundo que vive. (SOUZA e SOUZA, 2017, p. 65)

Foi então que, à época, sugerimos que na busca dessa formação ampliada a planificação curricular estivesse alicerçada numa perspectiva de formação para além de grades curriculares. Ou seja, a planificação do currículo não era apenas uma questão estética, mas, sobretudo, uma forma de fazer frente a um currículo que valorizasse "apenas a formação específica em detrimento das bases sociais e políticas, essas ultimas tão necessárias para compreensão da vida e educação no/do campo (SOUZA e SOUZA, 2017, p. 65).

Sendo assim, balizamos nossas proposições nos estudos que concebem e organizam os currículos por meio de Mandalas. Essa decisão se deu em função da busca por uma lógica curricular que associasse a formação acadêmica aos aspectos inerentes à vida no campo. Foi então que a planificação da matriz curricular ganhou o mesmo formato proposto pela Tecnologia Social conhecida como PAIS (Produção Agroecológica Integrada Sustentável). Ressaltamos que, com algumas alterações feitas na proposta curricular as intencionalidades iniciais foram se perdendo. Contudo, reafirmamos que continuamos defendendo um processo formativo de totalidade e, sendo assim, até mesmo a idealização do desenho curricular faz grande diferença.
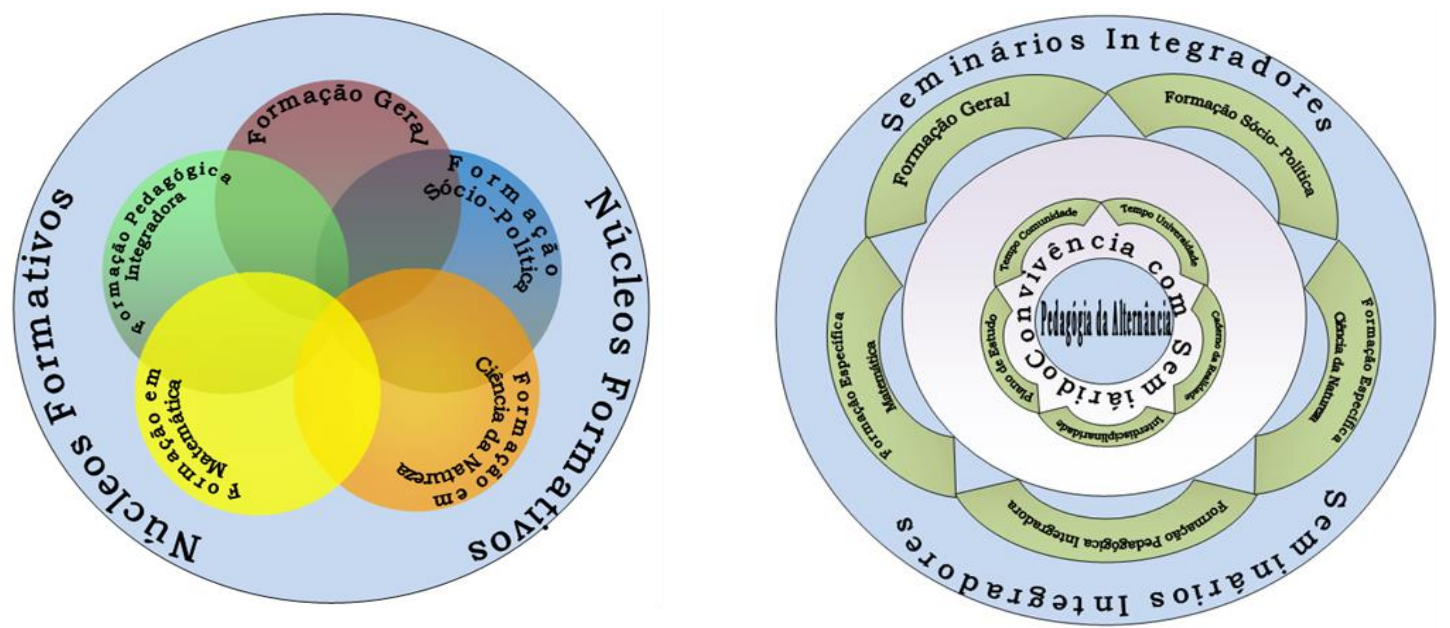

Fonte: Projeto Pedagógico do Curso de Educação do Campo CETENS/UFRB (2013) Criação Gráfica: autores 


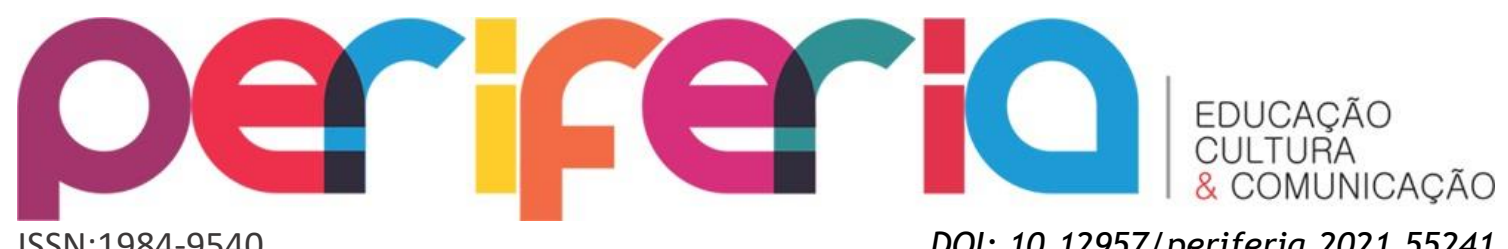

ISSN:1984-9540

DOI: 10.12957/periferia.2021.55241

A ideia das Mandalas Curriculares fortalece as possibilidades de trocas, diálogos e mediações entre as construções nos tempos formativos, pois relacionam-se como os movimentos de horizontalidade e complementaridade, compondo assim "um sistema dinâmico, imprevisível, um árduo trabalho de liberdade, de devir histórico, um esforço incessante de nos reconhecer em constante mutação" (BRASIL, 2009, p. 23).

De que valeria uma planificação curricular se não existisse uma perspectiva epistemológica de currículo que sustentasse a proposta? Sem uma base conceitual seria um mero desenho. Foi então que, para compor essa base, juntamente com os aportes interdisciplinares, trouxemos a perspectiva intertranscultural.

A primeira acepção que temos desta perspectiva é a ideia de movimento e construção que dela advém. De acordo com Padilha (2004, p. 247), um currículo organizado na perspectiva intertranscultural não pode ser visto como um conjunto ou corpo de conhecimentos previamente definidos, pois, "parafraseando Paulo Freire, o currículo intertranscultural não é. O currículo intertranscultural está sendo. " (PADILHA, 2004, p. 247).

$O$ autor segue ainda nos dizendo que não se trata de uma nova concepção de currículo, a disputar espaço com concepções anteriores, para ser, em seguida, superadas por uma nova concepção. Antes é uma forma de colocar o currículo e as pessoas que dele são partícipes em movimento construtivo, pois, como afirma Padilha (2011, p. 49), um currículo vivo pressupõe "todo processo educacional intencional, que tem como ponto de partida as pessoas, os coletivos humanos e as relações interculturais que eles estabelecem ente si e com o mundo em que vivem. Nasce do reconhecimento das histórias de vida, das culturas e das identidades das pessoas".

$\mathrm{Na}$ busca dessa interpenetração dos aspectos curriculares e das histórias de formadores e estudantes, foi proposta a organização dos campos de saberes em Núcleos Formativos. Estes foram pensados como forma de articular ensino, pesquisa e extensão a partir das perspectivas interdisciplinar e intertranscultural. Assim, de acordo com o Projeto Pedagógico do Curso (2013), temos: 


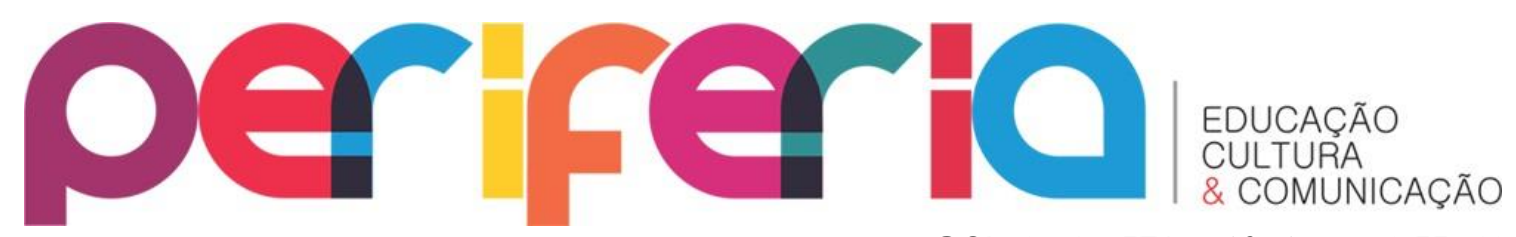

ISSN:1984-9540

DOI: $10.12957 /$ periferia.2021.55241

- Núcleo de Formação Geral: pensado para proporcionar aos discentes subsídios para a construção da formação intelectual, articulando aspectos dos conhecimentos gerais que serão fundantes para diálogo com os conteúdos de outros núcleos;

- Núcleo de Formação Sociopolítica: concebido para proporcionar ao graduando subsídios para construção da formação sociopolítica com base nos estudos acerca das políticas educacionais através da inserção de temas para Educação do Campo relacionados à inclusão social, diversidade e pertencimento ao território;

- Núcleo de Formação Pedagógica Integradora: concebido para proporcionar ao graduando o estudo sobre teorias educacionais e pressupostos políticospedagógicos que orientam a ação do professor e para gestão dos processos educativos, escolares e não-escolares. Tem ainda o papel de promover a integração das atividades de tempo-universidade e tempo-comunidade;

- Núcleo de Formação em Ciências da Natureza: concebido para proporcionar ao graduando uma sólida formação teórico-prática, visando o desenvolvimento de habilidades e competências para a atuação nas áreas de conhecimentos que integram as Ciências da Natureza;

- Núcleo de Formação em Matemática: concebido para proporcionar ao graduando uma sólida formação teórico-prática, visando o desenvolvimento de competências para a atuação no campo do ensino de Matemática.

A explanação acerca da estrutura do curso teve como objetivo evidenciar que, desde a concepção da Licenciatura houve uma preocupação na busca pela superação da dicotomia teoria-prática. Esta superação também precisa ser considerada na organização dos Estágios Curriculares do Curso. Em se tratando de um curso sustentado pela Pedagogia da Alternância, esta dicotomização e o status salvacionista dos Estágios não podem predominar. Para isso, oferecemos nossas contribuições para vencermos as amarrar impostas aos Estágios pela organização curricular convencional. 


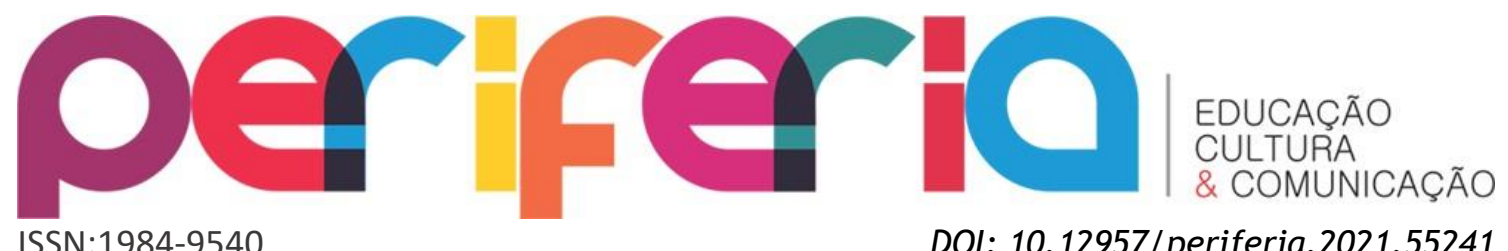

ISSN:1984-9540

DOI: $10.12957 /$ periferia.2021.55241

\section{A PESQUISA PARTICIPANTE COMO EIXO DO ESTÁGIO EM AMBIENTES NÃO ESCOLARES}

$\mathrm{Na}$ proposta de Estágio em Ambientes Não Escolares a Pesquisa Participante oferece os fundamentos do percurso metodológico. A consolidação do Estágio tem como aporte um Plano de Ação, constituído de cinco etapas: Observação Participante; Planejamento; Execução; Avaliação e Socialização. Desse modo, intentamos oferecer aos nossos discentes uma alternativa inovadora que venha proporcionar o desenvolvimento da educação científica, por conseguinte, imbricada nos processos de formação docente. Essa perspectiva se torna algo real a partir do momento em que a formação do educador do campo é ressignificada a partir da concepção do Estágio como pesquisa.

Ressaltamos que o itinerário investigativo da Pesquisa Participante se encontra amparado nos pressupostos da investigação social. Assim, o efetivo desenvolvimento do percurso metodológico dependerá da plena participação da comunidade, não só no desenvolvimento das atividades, mas, sobretudo, na análise de sua própria realidade. Desse modo, a participação social qualificada tem uma relação direta com os benefícios que os participantes da investigação podem alcançar. Isso se deve ao fato de ser a Pesquisa Participante uma atividade educativa de investigação e ação social (BRANDÃO, 1984).

Carlos Rodrigues Brandão (1984) também nos fala que a legitimação da Pesquisa Participante requer uma descrição eficiente e comprometida da realidade observada, principalmente dos significados atribuídos pelas pessoas que organizam suas vidas nessa realidade. Essa atribuição de significados, efetivada por meio das narrativas, requer que o estagiário/pesquisador estabeleça uma relação dialógica que envolva suas vivências e as experiências dos sujeitos participantes. Esse modo de agir dará a tônica para um Estágio como pesquisa ao se instaurar um processo de (re)construção das trajetórias acadêmicas e existenciais, onde a atribuição de novos significados aconteça.

Portanto, no âmbito do Estágio, a Pesquisa Participante, consiste na participação dos estudantes da Educação do Campo no cotidiano de instituições não escolares. São nesses ambientes que o contato direto com atores sociais 


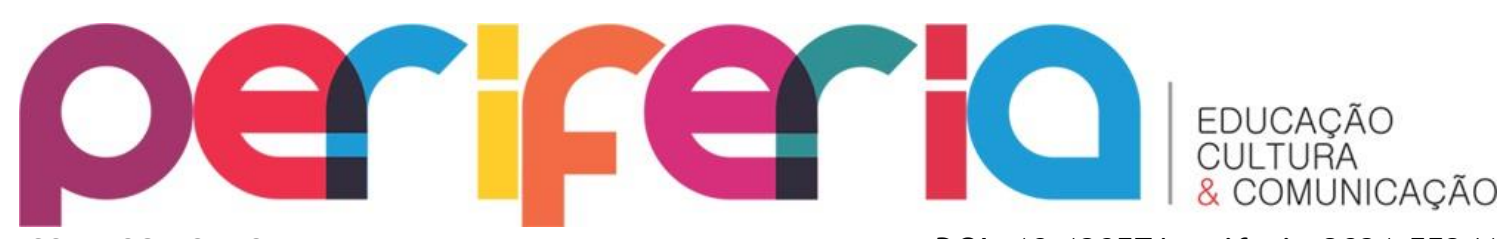

ISSN:1984-9540

DOI: $10.12957 /$ periferia.2021.55241

acontece. Quando atuamos com esse componente curricular foi possível contribuir com as atividades realizadas nessas instituições e, concomitantemente, começamos a produzir dados que possivelmente não seriam perceptíveis nas tradicionais fases de observação e coparticipação aplicadas em certos tipos de Estágio.

No Plano de Ação, o passo inicial é a Observação Participante. Esse é o momento em que o estudante estabelecerá aproximações com a instituição campo de estágio. Mesmo que já tenha realizado outras atividades nessa instituição, será necessário novos protocolos e novas posturas, pois agora as ações serão norteadas por um percurso metodológico de pesquisa. Os estudantes objetivarão conhecer o funcionamento, dialogar sobre as atividades desenvolvidas, participar de reuniões, apresentar os documentos de Estágio e conhecer os membros da instituição. Essa etapa será fundamental para construção do diagnóstico da realidade da instituição.

A observação, na perspectiva da Pesquisa Participante, constitui-se num procedimento básico que pode fortalecer a consecução do Estágio. De acordo com Serva e Júnior (1995), neste tipo de ação o "observador e observado encontram-se face a face. A coleta de dados se dá no próprio ambiente natural de vida dos observados, que passam a ser vistos não mais como objetos de pesquisa, mas como sujeitos que interagem em dado projeto de estudos" ( $p$. 25).

A etapa de Planejamento será sustentada por um diálogo ampliado que envolverá o Professor Orientador de Estágio, o Supervisor (Educador Social e/ou lideranças) e o Estagiário. Assim, a preparação das práticas sociais educativas não será idealizada no "olimpo acadêmico" para apenas ser despejado na instituição parceira. Outra orientação para essa etapa é que as ações a serem executadas dialoguem tanto com os conteúdos vivenciados durante o TempoUniversidade tanto com a realidade da instituição concedente e o contexto sócio-político-econômico da localidade. É o momento da definição do problema de pesquisa a ser desenvolvido.

A Execução é uma etapa que se estrutura a partir da ação mediadora que permite ao Estagiário não só construir seu itinerário de aprendizagem, mas, 


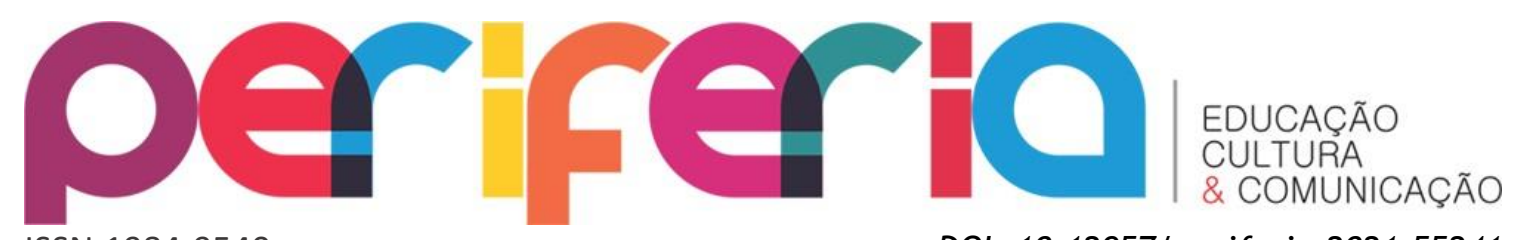

ISSN:1984-9540

DOI: $10.12957 /$ periferia.2021.55241 sobretudo, contribuir com a transformação social da instituição onde o Estágio se realiza. Nessa etapa as ações poderão ser desenvolvidas por meio de Oficinas, Sequências Didáticas ou outras atividades previstas no Projeto de Estágio. É o momento do desenvolvimento do Projeto de Intervenção.

A etapa de Avaliação permitirá o acompanhamento processual e a avaliação das ações. As atividades a serem desenvolvidas serão registradas em diários de campo que, consequentemente, orientarão os relatórios parciais de pesquisa e o relatório final de Estágio. É o momento de verificar o alcance das ações elaboradas para responder o problema de pesquisa.

A etapa de Socialização se divide em duas ações. Uma é apresentação dos resultados para os membros da instituição concedente. A outra é o relato de experiência no Seminário Integrador. Seminário é um momento de integração onde o conjunto dos estudantes exercem o direito da fala.

As ações relacionadas às práticas de Estágios Curriculares na LEdoC vêm se preocupando com a oferta de uma formação que vá além dos aspectos teóricos e técnicos do Componente Curricular Estágio que, muitas vezes, não estão relacionados aos problemas e demandas sociais das localidades onde se desenvolvem. 0 que se tem buscado é a superação de um modelo sustentado na execução de etapas técnicas e distante da realidade dos campos de Estágio. Por outro lado, aceitamos o desafio de construir um Estágio sustentado numa dimensão investigativa que possibilite o exercício de procedimentos metodológicos da pesquisa científica, pois, articulando pesquisa e ação nos Estágios poderemos contribuir para superação do tecnicismo que envolve alguns Estágios na formação de professores.

Nesse sentido, o Estágio deve se tornar um espaço onde a relação teoria e prática se materialize através da articulação dos saberes científicos e pedagógicos à experiência de vida escolar e não escolar. Um momento que possibilite aos estudantes aportes científicos utilizados para investigar tanto os espaços escolares quanto os não escolares, as organizações sociais e, sobretudo, implicações mútuas dessas instituições com a sociedade e vice-versa.

É nessa perspectiva que o trabalho desenvolvido no Componente Curricular Estágio em Ambientes Não Escolares vem edificando sua organização 


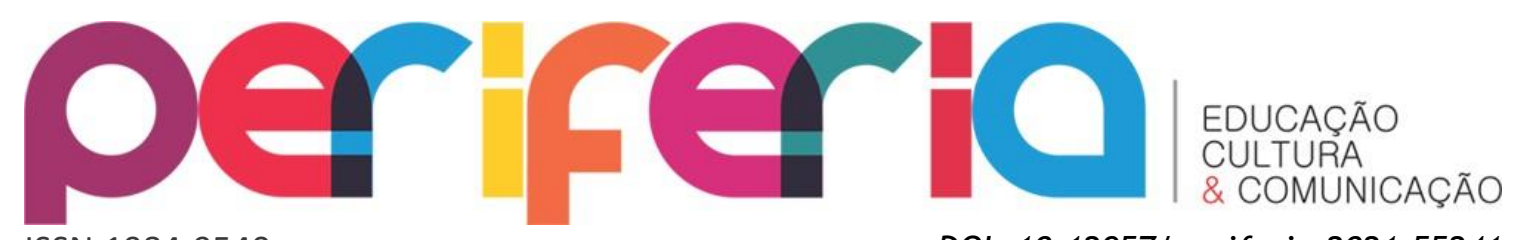

ISSN:1984-9540

DOI: 10.12957/periferia.2021.55241

didático-metodológica. A intenção é oferecer possibilidades de construção de conhecimentos a partir do diálogo entre teorias e práticas, entre os principais aspectos dos saberes produzidos nos espaços não escolares e, principalmente, promovendo a necessária autonomia na produção dos saberes da docência, também nos espaços não formais. Acreditamos que desse modo poderão ser gerados novos conhecimentos capazes de se transformar em ações de intervenção da realidade educativa e social.

\section{REPRESENTAÇÕES DOS (AS) DISCENTES SOBRE ESTÁGIO NA PERSPECTIVA INVESTIGATIVA}

Para se chegar na execução do Estágio na perspectiva investigativa as etapas apresentadas anteriormente foram fundamentais. Nos momentos de orientação no Tempo-Universidade os pormenores da Pesquisa Participante foram devidamente estudados, bem como foram retomados alguns princípios e estratégias da metodologia científica como forma de construirmos coletivamente compreensões sobre a temática e o ambiente não escolar onde se desenvolveram as ações investigativas do Estágio.

Um dos projetos de estágio foi realizado na Associação Quilombola de Barreiros de Itaguaçu da Bahia. Teve como parceiros os associados adultos, os jovens associados e filhos de associados. 0 objetivo foi desenvolver ações que permitissem a compreensão da diferença/consequência do Agronegócio e da Agricultura Familiar. Assim, pelas características dos parceiros, bem como da localidade, as atividades propostas enfatizaram a importância da Agricultura Familiar, não só para o sustento das famílias, como para o meio ambiente. Foram desenvolvidas oficinas, inicialmente com pequenos vídeos sobre o agronegócio e a agricultura familiar, com o intuito de contextualizar ambas realidades, bem como despertar o interesse dos jovens e dos associados pela agricultura familiar saudável e socialmente sustentável.

O Projeto em questão teve como proponentes e executores três licenciandos. No relatório final de estágio eles se apresentam e falam sobre suas percepções do trabalho realizado: 


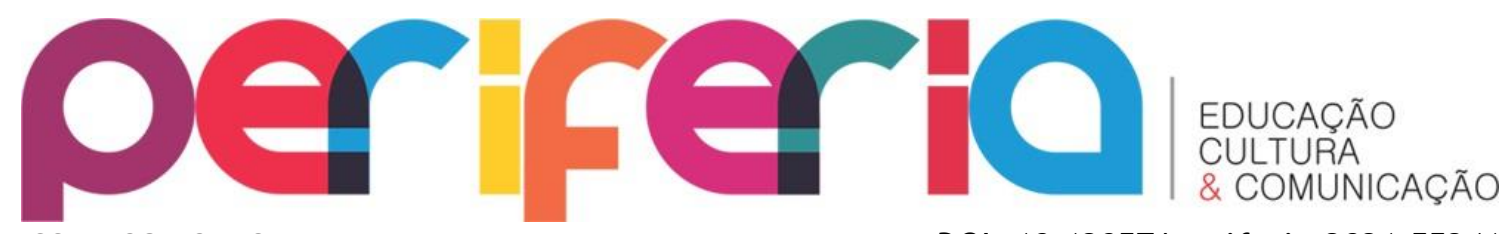

DOI: 10.12957/periferia.2021.55241

Nós somos membros da Associação Quilombola Ernestino Martins de Souza. Observamos a dificuldade dos jovens da nossa comunidade e dos associados em compreenderem as consequências devastadoras para o meio ambiente e, consequentemente, para a sociedade do agronegócio. Sabemos que cinco oficinas não são suficientes, mas acreditamos que seja possível despertar os associados e jovens para a importância da agricultura familiar socialmente sustentável.

Os jovens estudantes ao objetivarem as ações por meio de oficinas,conseguiram apresentar para os colegas de Associação a importância da organização, das lutas e resistências. Aquilo que os unem, a agricultura familiar, permitiu o desenvolvimento de ações que tanto serviram para colocarem os conhecimentos adquiridos no curso quanto sensibilizar os agricultores para necessidade da organização social e política. Os jovens Joab Diolino, Regivan dos Santos e Tiago Diolino relatam alguns resultados obtidos.

\begin{abstract}
Um dos experimentos que realizamos nas oficinas pudemos demonstrar a capacidade de energia que algumas frutas e verduras possuem. Ao utilizarmos as frutas como "pilhas orgânicas" demonstramos ser possível acender uma lâmpada, pois, as mesmas apresentam um ciclo biogeoquímico que permite tal ação. Aproveitamos o gancho para falar do descarte adequado de alguns aparelhos, ou melhor, fizemos atividades onde esses aparelhos foram reutilizados. Com as atividades também pudemos apresentar os produtos orgânicos produzidos pelos agricultores da associação, como também os seus benefícios. Por outro lado, apresentamos algumas consequências danosas do uso de produtos cultivados com agrotóxicos.
\end{abstract}

É possível percebermos que o olhar dos licenciandos para a realidade da qual fazem parte muda, assim como muda a forma que passam a ser visto na comunidade e na própria Associação. Não chega a ser regra, muito menos é uma exceção, mas, esses jovens da Educação do Campo acabam se tornando líderes precoces nas suas Associações. Quando não, despertam para participação nesses grupos sociais, coisa que antes de olharem seu lugar com olhos de investigadores não lhes apetecia.

Uma outra ação de Estágio que permitiu um coletivo olhar para seus processos de lutas e resistências foi proposto e desenvolvido pelo discente Fábio 


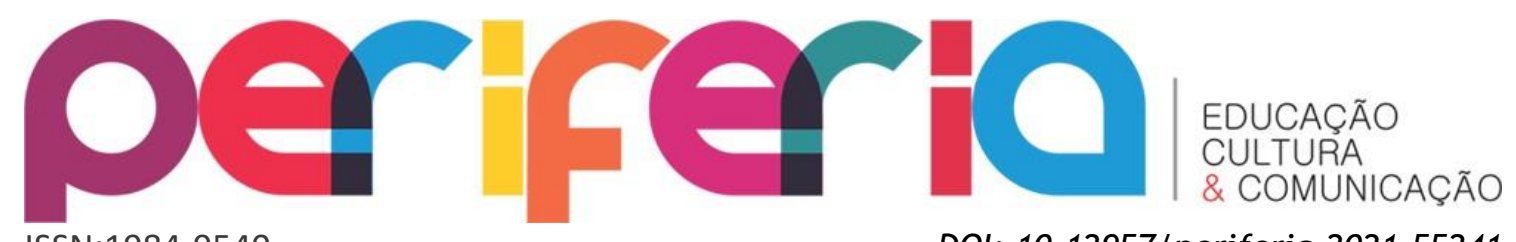

ISSN:1984-9540

DOI: $10.12957 /$ periferia. 2021.55241

Tarrão. Teve como título: A força de um povo tem como alicerce as suas culturas.

A Associação Comunitária dos Trabalhadores Rurais Quilombola de Cajueiro foi o ambiente não escolar que acolheu o referido trabalho. 0 público participante, associados e jovens da comunidade. A metodologia flexível respeitou os saberes populares da comunidade e, através dos diálogos o licenciando conseguiu a participação direta dos envolvidos. As atividades do Estágio, numa perspectiva investigativa, buscaram problematizar os impactos na cultura local após a chegada da energia elétrica e as novas tecnologias na comunidade. De acordo o licenciando: "no decorrer do Estágio aconteceram muitas intervenções que deram consistência a necessidade de discussão acerca dessa temática, incentivando o desenvolvimento de uma possível pesquisa científica para melhor analisar os dados".

Percebemos assim que, a compreensão das possibilidades investigativas foi sendo percebidas desde a elaboração das projeções metodológicas e procedimentais do Estágio e, sobretudo, quando passaram a vivenciar diretamente as atividades na Associação.

Outros tantos relatos das descobertas realizadas no Estágio Curricular em Ambientes Não Escolares apontaram situações que primaram pela organização social e políticas de instituições que agrupam trabalhadores rurais. Importante destacar que atividades como as desenvolvidas acabam por contribuir para organização das lutas campesinas, pois, despertam novas lideranças, abrem uma outra perspectiva de participação e organização coletiva na comunidade, sobretudo, quando percebem que os conhecimentos que os jovens foram construir fora da comunidade podem ser revestidos para o bem comum da localidade.

\section{CONSIDERAÇÕES PROCESSUAIS}

A abrangência da temática e a limitação requerida por uma publicação desta natureza, deixa sensações duais. Por um lado, a sensação de dever cumprido, pois, é fundamental o registro e difusão das práxis pedagógicas 


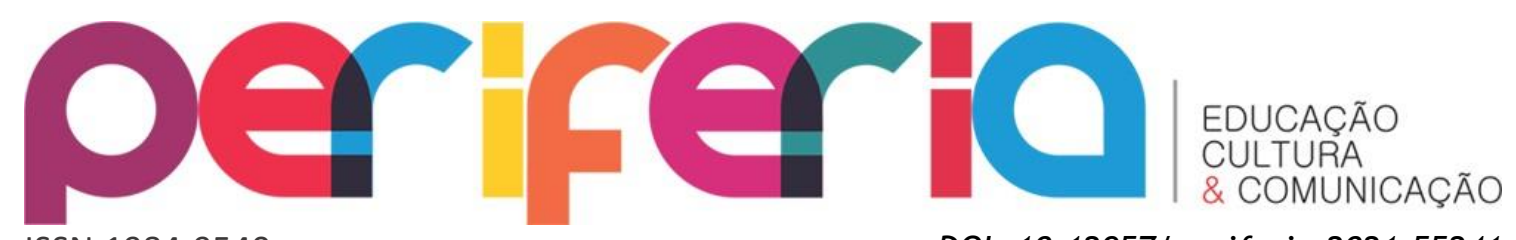

ISSN:1984-9540

DOI: $10.12957 /$ periferia.2021.55241

desenvolvidas numa universidade pública. Por outro lado, a sensação é que o fôlego permitiria avançar mais, no entanto, percebemos que a linha de chegada se impôs à nossa frente. Mas, fica o alento que ainda temos muito a caminhar.

Mesmo avistando a reta final ainda queremos demarcar que acreditamos num Estágio Curricular inserido numa dimensão formativa problematizadora, mas, ao mesmo tempo, que impulsione um olhar que venha redimensionar a formação e a prática docente.

A nossa sensação é que não dá para ficar apenas ouvindo o estrondo da árvore que cai. Precisamos sim escutar a floresta crescer. Portanto, quando nos predispomos a abordar o Estágio, para além das aparências, a simples caracterização do mesmo torna-se insuficiente. A partir da nossa prática docente, nos sentimos desafiados a desvelar as dificuldades que perpassam esse componente, bem como ir além das simples análises e opiniões através da apresentação de possibilidades para os mesmos. Isso é uma forma de colaborar para a luta e resistência dos povos do campo.

Guiados pelas percepções que nos possibilitam fazer, refletir e agir a partir dos Estágios, seguimos compromissados como o desenvolvimento do Curso, da Universidade, das instituições de Educação Básica, das instituições não formais e, sobretudo, compromissados com o desenvolvimento humano, político, epistemológico e afetivo dos discentes e docentes com quem compartilhamos nosso cotidiano acadêmico. Portanto, esse olhar ampliado acaba apontando outras possiblidades para o fortalecimento das lutas campesinas, pois, se faz necessário rompermos os muros institucionais e academicistas para proporcionar que docentes e discentes olhem a realidade de frente e, coletivamente, possamos levantar os problemas e buscarmos saídas. Isso é reexistir e resistir.

\section{REFERÊNCIAS}

BRANDÃO, C. R. Pesquisa Participante. São Paulo: Brasiliense, 1984.

BRASIL. Rede de saberes mais educação: pressupostos para projetos pedagógicos de educação integral: caderno para professores e diretores de escolas. - 1. ed. - Brasília: Ministério da Educação, 2009. 


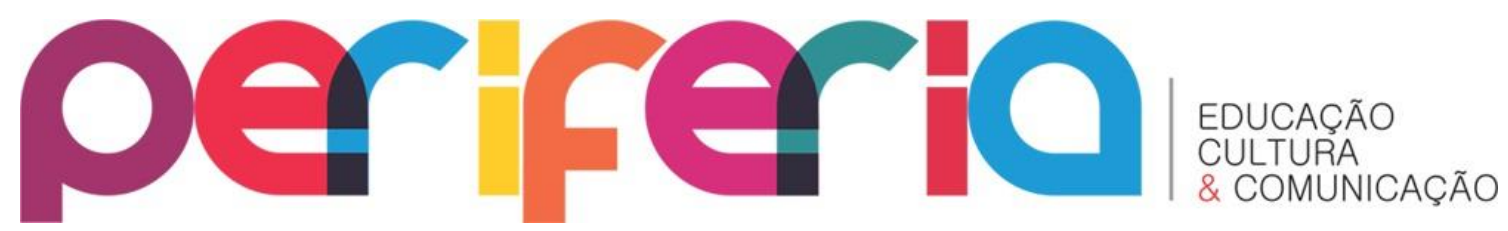

ISSN:1984-9540

DOI: 10.12957/periferia.2021.55241

FRIGOTTO, Gaudêncio. Cidadania e formação técnico-profissional: desafios neste fim de século. In: SILVA, Luiz Heron et al. (Org.). Novos mapas culturais, novas perspectivas educacionais. Porto Alegre: Sulina, 1996.

MOLINA, Mônica Castagna; MONTENEGRO, João Lopes de Albuquerque; OLIVEIRA, Liliane Lúcia N. de Aranha. Das desigualdades aos direitos: a exigência de políticas afirmativas para a promoção da equidade educacional no campo. Brasília: Conselho de Desenvolvimento Econômico e Social (CDES), 2009. Disponível em: http://www.gepec.ufscar.br/textos-1/textos-educacaodo-campo. Acesso em 04/06/20.

PADILHA, Paulo Roberto (org). FAVARÃO, Maria José, MARINE, Luiz. MORRIS, Erick. Educação para Cidadania Planetária: Currículo Interdisciplinar em Osasco. São Paulo, 2011.

PADILHA, Paulo Roberto. Currículo Intertranscultural: novos itinerários para educação. São Paulo: Cortez, 2004.

PELOSO, Ranulfo. Trabalho de Base: seleção de roteiros organizados pelos Cepis. - 1,ed - São Paulo: Expressão Popular, 2012.

SERVA, M.; JAIME JR, P. Observação participante e pesquisa em administração: uma postura antropológica. Revista de Administração de Empresas, São Paulo, v.35, n.1, p.64-79, mai/jun 1995.

SOUZA, Kleber Peixoto de. Estágio Curricular: a construção de uma ação pedagógica e investigativa. In.: CORREIA, Wilson Francisco (Org.). Formando Professores: caminhos da formação docente. Rio de Janeiro: Editora Ciência Moderna LTDA, 2012.

SOUZA, Leila Damiana A. dos S.; SOUZA, Kleber Peixoto de; SANTOS, Andreza Bispo dos Anjos; FERREIRA, Jucileide Souza. Sujeitos do campo: do silenciamento e invisibilidade à luta por direitos humanos. In.: GALVÃO, Nelma de Cássia Silva Sandes [et al.]. Educação, Tecnologia, Ambiente e Sustentabilidade: Perspectivas Multidisciplinares. Cruz das Almas, BA: EDUFRB, 2017.

UFRB. Projeto Pedagógico do Curso de Licenciatura em Educação do Campo. Centro de Ciência e Tecnologia em Energia e Sustentabilidade, da Universidade Federal do Recôncavo da Bahia (CETENS/UFRB). Feira de Santana, BA, 2013.

UFRB. Projeto Pedagógico do Curso de Licenciatura em Educação do Campo. Centro de Ciência e Tecnologia em Energia e Sustentabilidade, da Universidade Federal do Recôncavo da Bahia (CETENS/UFRB). Versão Atualizada. Feira de Santana, BA, 2018. 